\title{
A Typical Approach in Conceptual and Embodiment Design of Foldable Bicycle
}

\author{
Arunachalam M \\ Dept. of Production \\ Engineering, \\ PSG college of \\ Technology, \\ Coimbatore, \\ India
}

\author{
Arun Prakash R \\ Dept. of Production \\ Engineering, \\ PSG college of \\ Technology, \\ Coimbatore, \\ India
}

\author{
Rajesh R \\ Dept. of Production \\ Engineering, \\ PSG college of \\ Technology, \\ Coimbatore, \\ India
}

\begin{abstract}
The Conceptual design and Embodiment design are two of the important stages in a typical product design and development process. This study aims at generating different concepts for a foldable bicycle product using a systematic concept generation method and the best generated concepts have been selected using various concept selection methods. It also describes a systemic approach to material selection and FEA justify during embodiment design phase. Various design concepts have been generated from a range of available possible solutions to each product function by morphological matrix which was developed based on functions tree. The Pugh chart and numerical concept selection methods have been employed to select the best concepts that have been generated based on a set of criteria. In the Embodiment design phase, the Ashby method has been used for material selection for the selected design concept. The human comfort has been checked by Digital Human Modeling (DHM) Technology. In addition to the material selection process, the proposed design of the foldable bicycle has also been analyzed for its safety by FEA and Fatigue analysis.
\end{abstract}

\section{Key words}

Conceptual design, Pugh chart, Embodiment design, Ashby material selection, DHM and FEA analysis.

\section{INTRODUCTION}

A product is a solution to a problem, which has been raised by a customer. A typical product development process, has various phases.

The first phase understanding the opportunity deals with the identification of customer needs which define the problem to be addressed various tools like customer survey interviews and interviews are used to understand the customer needs. The next stage conceptual design deals with finding the solutions to solve the problem. Various methods like functions modeling, concept engineering are used in this phase. The concept engineering is generally considered as the final outcome of developing a concept, where the concept generation and concept selection activities are done.

The final stage implementing a concept deals with the embodiment design, design for $\mathrm{x}$ etc. It is the phase where the material selection, dimensions \& tolerances for the product is finalized. In this study, the modern product development process has been followed to address the market study. A new foldable bicycle has been designed based on the limitations of the current design.

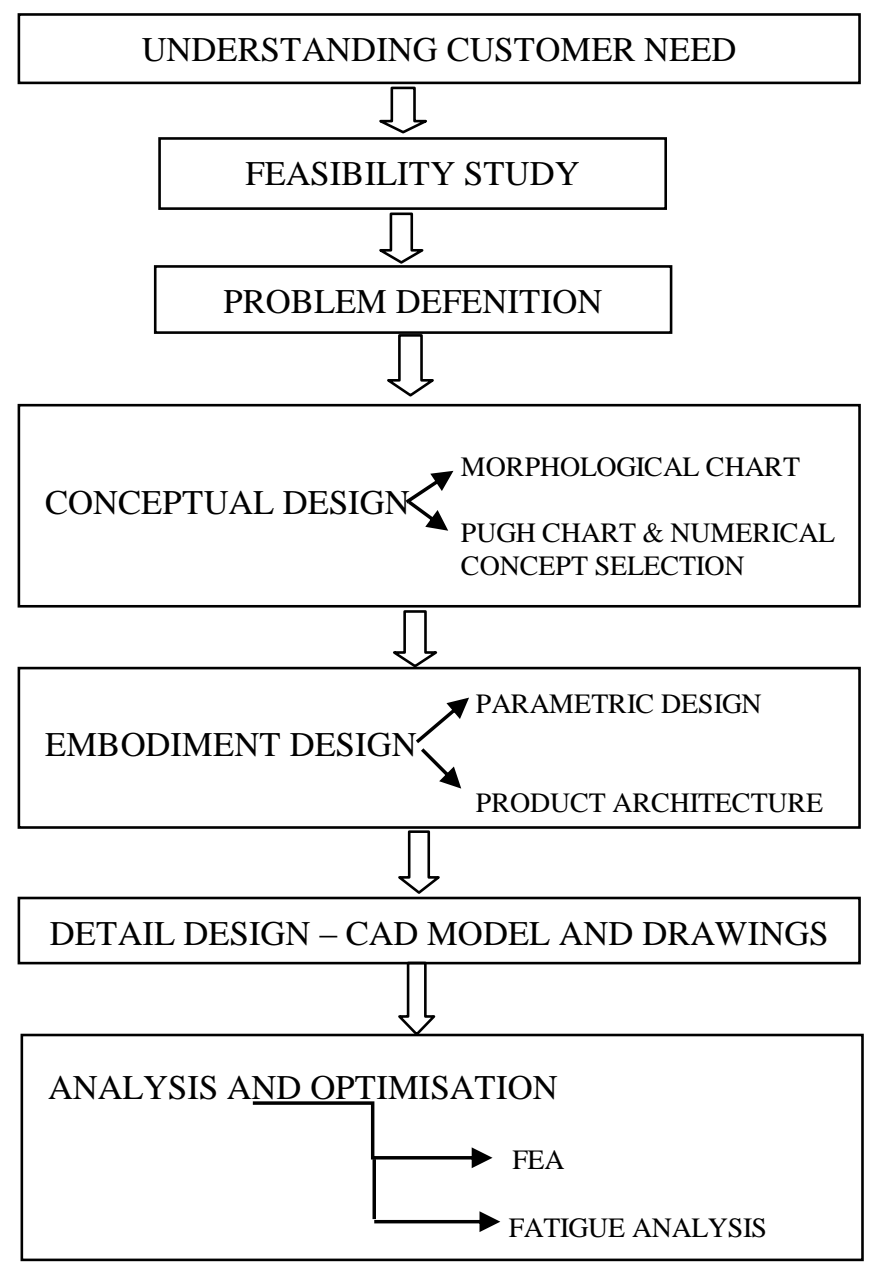

Fig 1: Modern product development process 


\section{THE PROBLEM}

The need for a foldable bicycle arise from the market survey which reveals that the normal bicycles that are available in market are of heavy weight, less compact and unable to be carried to various places during traveling by a commuter. It is not transportable from one place to other far off places. This leads to the commuter to heavily rely on local transport. Hence it is understood that the foldable bicycles are an alternative to the conventional bicycles.

From the field survey it has been found that even though there are foldable bicycles in the market, they are found to be less portable, even though they are foldable. The foldable configuration are also found to be not simple which leads to difficulty in transporting it. This leads to the requirement of designing and developing a new foldable bicycle made out of weightless material that can be easily transportable and also very portable. This work addresses the above problem by proposing a new foldable bicycle design which overcomes the above mentioned problem in the existing designs.

\section{PROBLEM RELATED WORK}

Literature review of electronic media, journal publications, books and technical reports explain various inventions of foldable bicycle. The literatures are used to understand the past inventions of foldable bicycle. [1] In 1986, Nishimura et al invented a foldable bicycle frame which has a vertical center tube at a mid-portion of the bicycle frame. The front half of the bicycle frame can be folded or extended. [2] Beech invented a portable cycle-type exercising device capable of being easily erected for use and compactly folded for convenient storage in a relatively small area during periods of non-use. [3] In 1986, Chiu invented a mini foldable bicycle which has a single front wheel for steering and a pair of adjacent wheels at rear for propelling the bicycle. The bicycle is small and light, and is made foldable so that it can be reduced to a very small package for the convenience of being transported. [4] In 1990, Huppe invented the invention provide extended at an angle from a rear- wheel fork, pedal crank can be placed on a higher frame or adjustable vertically upwards to avoid rocks and bushes in mountain riding or downwards for lower obstacles in street riding. [5] In 1995, Ching-Tsung invented a foldable bicycle with many links that are made to join the components of the bicycle such as handlebar, seat tube, top tube, head tube and down tube. [6] In 2000, Herder invented a foldable bicycle frame member with first and second shafts connected pivotally at one end and a locking unit for retaining releasable. [7] In 2001, Ibarra invented a novel bicycle which combine a skateboard and bicycle. The bicycle is provided with normal bicycle handle bar and the rear side of the bicycle is attached with the skateboard. There is no chain drive. Manual pull energy is the source of power to move. [8] In 2007, Sanders invented a foldable frame assembly with hinge. The hinging action allows the bicycle to get foldable as well as provide a rigid structure while riding. The aesthetical appearance is also good. [9] In 2010, Yi-Cheng Lin invented a laterally moving foldable bicycle consisting of the mechanical components like a sleeve, upward directed notch, support tube, auxiliary wheel and threaded lever.

In all above invention, the role of joints and links are observed to be important. Some of the journals about bicycle frame joints and links are reviewed. [10] In 1988 Zane et al, invented the clamp, which is releasable and has a secured lock to a foldable bicycle frame. [11] In 1996 Pan, used a joint for the bicycle frame. The joint includes a composite material which has a first tubular member, and a metal second tubular member fitting with a laterally extending insertion portion

There are a variety of inventions of the foldable bicycle so far. Hence, in the present paper an attempt has been made to design and develop a foldable bicycle by employing a systematic approach conceptual design and embodiment design methods.

\section{FUNCTIONAL MODELLING}

The functional modelling is nothing but establishing functional structure of the product of interest. [14] Solution principles or designs based on conventional methods do not provide required design when latest technologies and inventions are to be used. The crux of the problem should be expressed as a list of the required functions and essential constraints. Fig. $2 \& 3$ show a simple black box diagram and functional tree of foldable bicycle respectively. The created functional tree has been developed based on the need statement. The need statement has been obtained by the small field survey and literature survey.

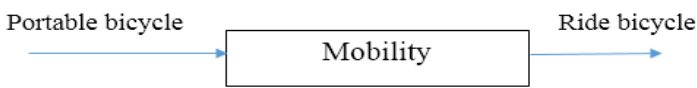

Fig 2: Simple black box of foldable bicycle

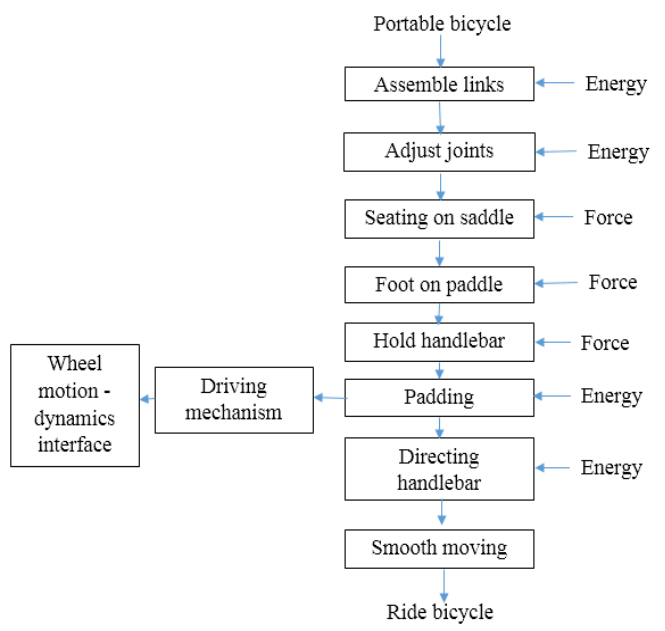

Fig 3: Functional tree of foldable bicycle

\section{CONCEPTUAL DESIGN}

As mentioned before, conceptual design is one of the important stages of a product design. After functional modelling, various concepts will be iterated by various concept generation methods like Traditional brainstorming, brain-ball, and C-sketch/6-3-5 method.

\subsection{Conceptual generation}

The main motivation of concept generation is to develop more concepts in order to satisfy functional needs of the product. Morphological analysis tool is one of the most powerful and quite widely used concept generating tools. It resembles a matrix of rows and columns as shown in fig. 4. It develops concepts for each product sub-function. Once the concepts are developed the morphological chart is developed as show below.

I. For each sub function, list the solution

II. Draw up the matrix table containing all the possible sub solutions.

III. Determine the feasible combination.

iv. Draw the conceptual sketches based on the feasible combinations 


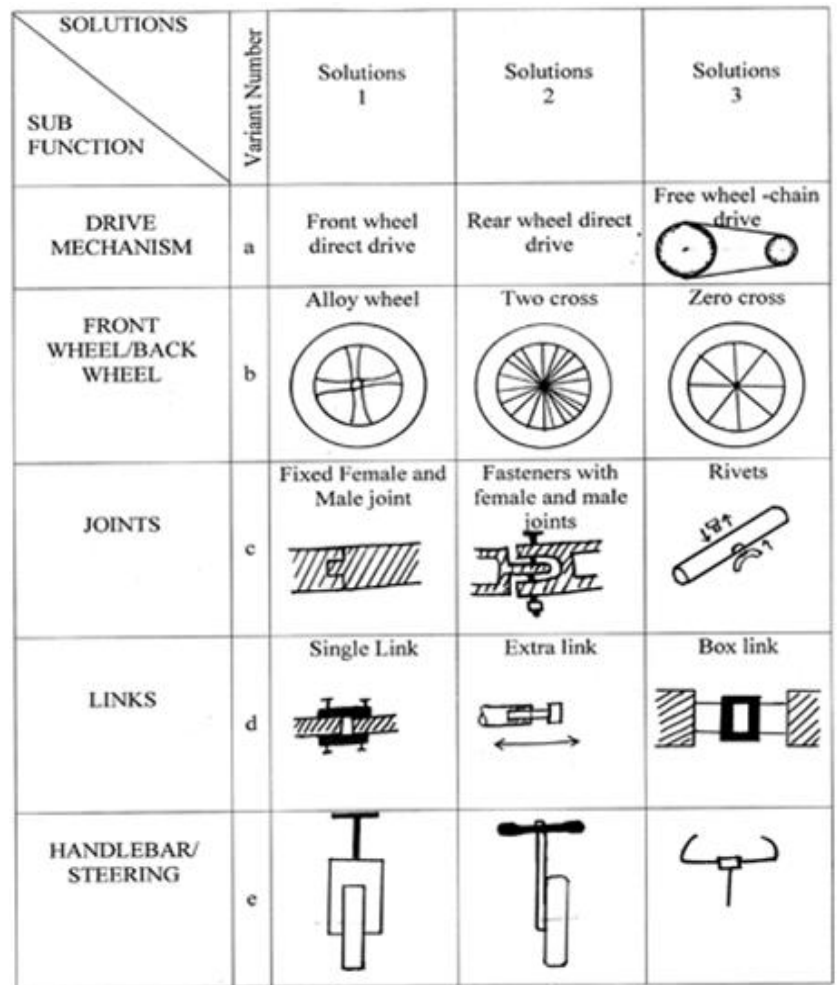

Fig 4. Morphological analysis chart

Based on the above four steps, various concepts have been evolved. Different concepts that have been generated from the morphological chart are show in fig. 6-14.

\subsection{Concept evaluation and selection}

Morphological chat may provide a lot of solutions or concepts to the problem, but not all of these solutions are feasible or able to be accomplished effectively. At this stage, the designer begins to limit the possible designs based on Standard specification, manufacturability, cost and other factors which are relevant to the problem.

In a typical product development process, once the different product concepts are generated, the generated concepts have to be evaluated to select the best concept among the various available concepts. Pugh chart and numerical concept selection are two of the most important methods that are used during concept selection process. In the above concept evaluating processes the alternatives are evaluated to find out the most effective concept to be developed. The first step in the concept evaluation process is to establish the evaluation criteria on which the concepts are to be selected. These criteria mainly depends on the type of product to be designed. Hence it differs from product to product.

\subsubsection{Pugh chart}

The table 1 shows Pugh chart that has been developed for a foldable bicycle product. The criteria chosen for this foldable bicycle is based on ergonomics, cost of product, the basic features needed for the product like the ease of fold ability, ease of assembly, weight of the product, etc.

The alternative concepts solutions are evaluated taking the existing product available in the market as the datum concept. The concept solutions are evaluated for each of the above mentioned criteria. The ranking of the alternative is based on the scale such as $(-, 0,+)$ where a $(-)$ is worse than a $(0)$, which is worse than a (+).
If a design concept is offering a better performance than the datum concept for a specific criteria then the particular design concept is assigned a $(+)$ rank. If it's offering a worse performance than the datum a (-) rank is assigned. If the performance of the datum and a design concepts is same for a specific criteria, a (0) rank is assigned.

The net score is obtained for each design concept based on the ranking. The concept that has the highest score over the other concepts is selected as the best concept based on Pugh chart methodology.

\subsubsection{Numerical concept selection}

Ref. [13], In the numerical concept selection method the concept solution are evaluated by listing it along the columns of matrix. The criteria that form the basis of the selection are listed along the row. The solution is evaluated based on each criterion and are assigned ranking from the range (R). Table 2 shows Numerical concept selection chart of foldable bicycle.

$$
\mathrm{R}=(--,-, \sqrt{ },+,++)
$$

In the evaluation process the ranking values are added for each alternative. The alternative with the highest score is selected as the best concept.

\section{EMBODIMENT DESIGN}

[14] At this stage of the design process, the designer starts what can be called as the embodiment design stage. The word embody means "to represent an idea". There are various important stages that are carried out in the Embodiment design. The stages are Human comfort check stage, material selection, cross section selection, and CAD model. All the above mentioned stages have been carried out in this study. Some stages are sequential activities and other few are non-sequential activities.

\subsection{Human comfort check using DHM's}

In general, DHM's Technology can be used for the product investigation before beginning the actual production [20]. In this study case this tool is used to check the human comfort like knee clearance, paddling reach, handlebar reach etc.

The selected concept 4 is developed in CAD. The DH model is developed based on the Indian Anthropometric Dimensions book [15] and few anthropometric dates are referenced from the journal [16]. The concept CAD and DH model is imported to the CATIA V5 as show in fig. 5. As mentioned before the human comfort like knee clearances, paddling reach, handle reach were verified and justified with DHM Technology. Table 3. Shows the percentile used in the CATIA V5 for human comfort check with DHM.

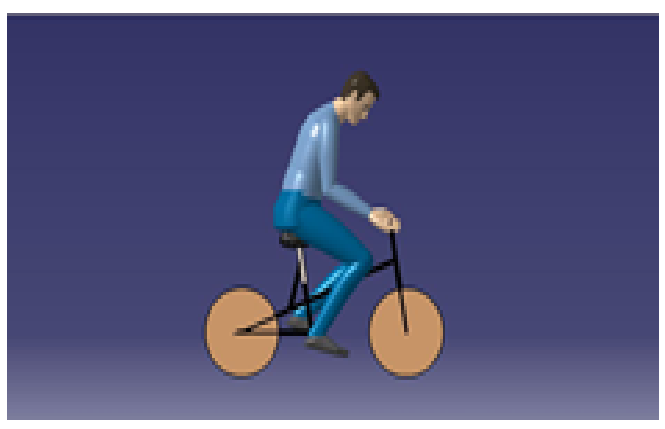

Fig 5. DHM model in Catia v5 

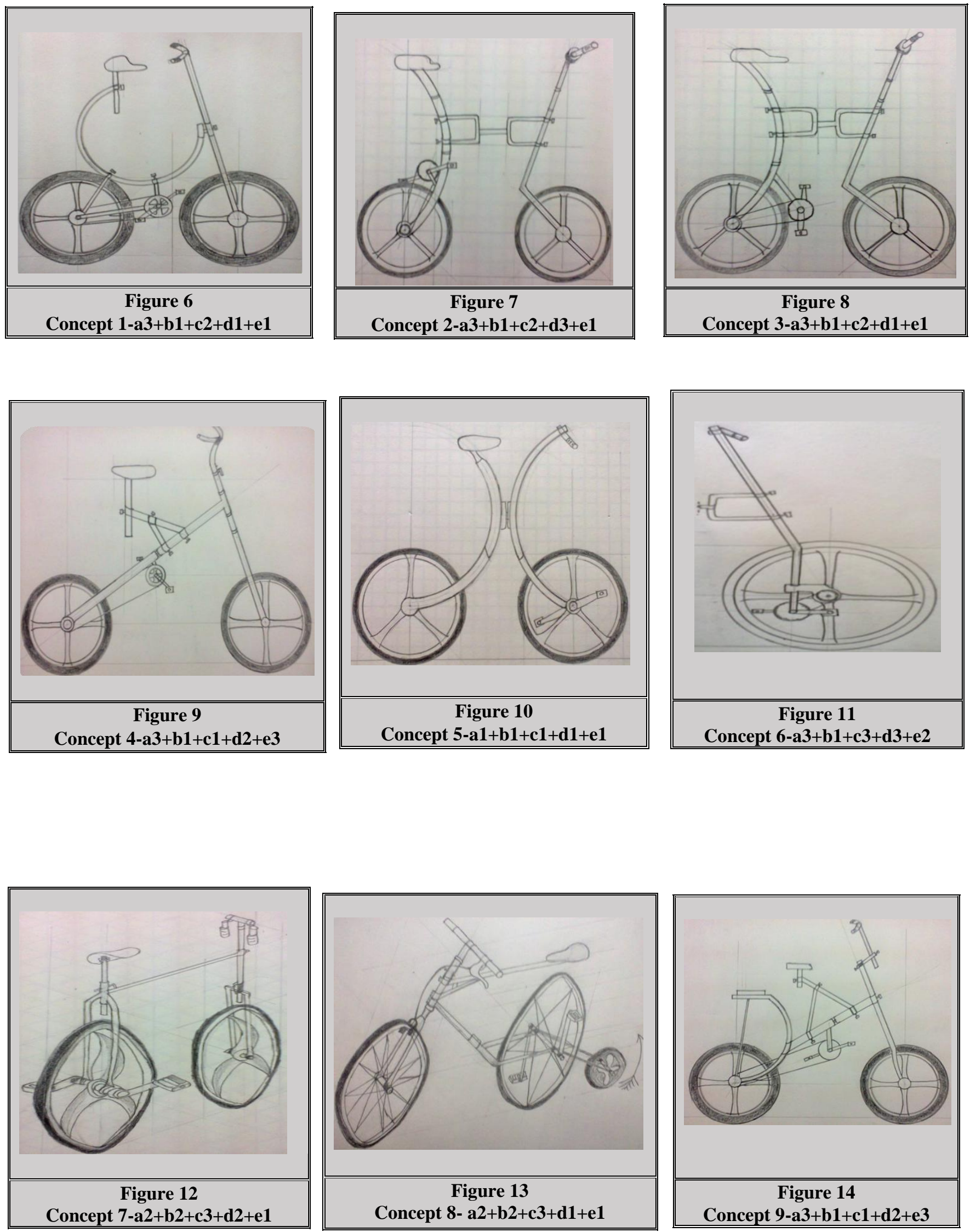
Table 1: Pugh concept selection chart

\begin{tabular}{|c|c|c|c|c|c|c|c|c|c|c|}
\hline \multirow[t]{2}{*}{ Pugh Concept Selection Chart } & \multirow[t]{2}{*}{ DATUM } & \multicolumn{9}{|c|}{ CONCEPTS } \\
\hline & & 1 & 2 & 3 & 4 & 5 & 6 & 7 & 8 & 9 \\
\hline $\begin{array}{l}\text { Criteria } 1 \text { - Easy of foldability - Assembly and } \\
\text { Disassembly }\end{array}$ & 0 & 1 & 1 & 1 & 1 & 1 & 1 & 1 & 1 & 1 \\
\hline Criteria 2 - Good Portability & 0 & 1 & -1 & -1 & 1 & -1 & 1 & 1 & -1 & -1 \\
\hline Criteria 3 - Easy of Maintainability & 0 & 0 & -1 & 0 & -1 & 1 & -1 & -1 & -1 & 0 \\
\hline Criteria 4 - Good Ergonomics & 0 & -1 & -1 & 0 & 0 & -1 & -1 & -1 & 1 & 1 \\
\hline Criteria 5 - Good Aesthetical Appearance & 0 & -1 & -1 & 1 & 1 & 1 & -1 & -1 & -1 & 1 \\
\hline Criteria 6 - Affordable MRP & 0 & -1 & -1 & -1 & 0 & 1 & 0 & 1 & 0 & 0 \\
\hline Criteria 7 - Easy of Adjustability & 0 & 1 & 1 & 1 & 1 & 0 & 0 & 0 & 1 & 1 \\
\hline $\mathrm{S}+$ & +0 & +3 & +2 & +3 & +4 & +4 & +2 & +3 & +3 & +4 \\
\hline S- & -0 & -3 & -5 & -2 & -1 & -2 & -3 & -3 & -3 & -1 \\
\hline $\mathrm{S}$ & 0 & 0 & -3 & 1 & 3 & 2 & -1 & 0 & 0 & 3 \\
\hline
\end{tabular}

Table 2: Numerical concept selection chart

\begin{tabular}{|c|c|c|c|}
\hline \multirow[t]{2}{*}{ Numerical Concept Selection Chart } & \multirow[t]{2}{*}{ DATUM } & \multicolumn{2}{|c|}{ CONCEPTS } \\
\hline & & 4 & 9 \\
\hline Criteria 1 - Easy of foldability - Assembly and Disassembly & $\sqrt{ }$ & ++ & + \\
\hline Criteria 2 - Good Portability & $\sqrt{ }$ & + & -- \\
\hline Criteria 3 - Easy of Maintainability & $\sqrt{ }$ & - & $\sqrt{ }$ \\
\hline Criteria 4 - Good Ergonomics & $\sqrt{ }$ & $\sqrt{ }$ & ++ \\
\hline Criteria 5 - Good Aesthetical Appearance & $\sqrt{ }$ & + & + \\
\hline Criteria 6 - Affordable MRP & $\sqrt{ }$ & $\sqrt{ }$ & - \\
\hline Criteria 7 - Easy of Adjustability & $\sqrt{ }$ & ++ & + \\
\hline$\sum--$ & 0 & 0 & 1 \\
\hline$\sum-$ & 0 & 1 & 1 \\
\hline$\sum \sqrt{ }$ & 7 & 2 & 1 \\
\hline$\sum+$ & 0 & 2 & 3 \\
\hline$\sum++$ & 0 & 2 & 1 \\
\hline overall $\sum$ & 0 & 5 & 2 \\
\hline
\end{tabular}

Table 3. Percentile used for checking

\begin{tabular}{|c|c|}
\hline Human comfort & $\begin{array}{c}\text { Indian Anthropometric } \\
\text { percentile used }\end{array}$ \\
\hline Nee clearance \& Paddling reach & $95^{\text {th }} \mathrm{p}$ \\
\hline Handle reach & $5^{\text {th }} \mathrm{p}$ \\
\hline
\end{tabular}

Table 4: FEA solution of foldable bicycle

\begin{tabular}{|c|c|c|c|c|}
\hline Load condition & Type of load & Von-misses Stress (Mpa) & Total deflection (mm) & $\begin{array}{c}\text { Tensile/yield strength } \\
\text { (Mpa) }\end{array}$ \\
\hline $120 \mathrm{~kg}$ & compression & 106 & 0.4 & $193-290$ \\
\hline $60 \mathrm{~kg}$ & Tensional & 54 & 0.2 & $241-320$ \\
\hline
\end{tabular}

Table 5: Fatigue simulation solution of foldable bicycle

\begin{tabular}{|c|c|c|c|c|c|}
\hline $\begin{array}{c}\text { Fatigue } \\
\text { cycle }\end{array}$ & Load condition & Type of load & $\begin{array}{c}\text { Von-misses Stress } \\
(\mathrm{Mpa})\end{array}$ & Total deflection (mm) & Fatigue strength (Mpa) \\
\hline 50000 & $120 \mathrm{~kg}$ & compression & 68 & 0.01 & 75 \\
\hline 50000 & $60 \mathrm{~kg}$ & Tensional & 34 & $6.2 \mathrm{e}^{\wedge}-3$ & 75 \\
\hline
\end{tabular}




\subsection{Material selection- Ashby method}

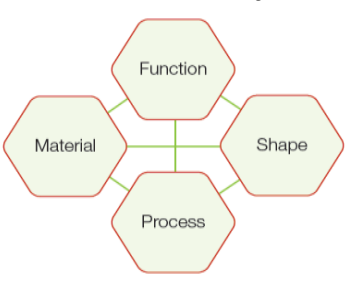

Fig 15. [19] The interaction between function, Material, process, and shape

As show in fig. 15 the selection of material is connected with the process and shape. The transformation that happens from initial raw material to the required shape is through the manfacturing process. It consists of primary forming processes (e.g., Casting and forging), material removal processes (machining, drilling), joining processes (e.g., Welding) and finishing processes (e.g., Painting or electroplating).

The essentials of a design-led material selection system is show in Fig.16. Its inputs are design requirements: function, constraints, and objectives.

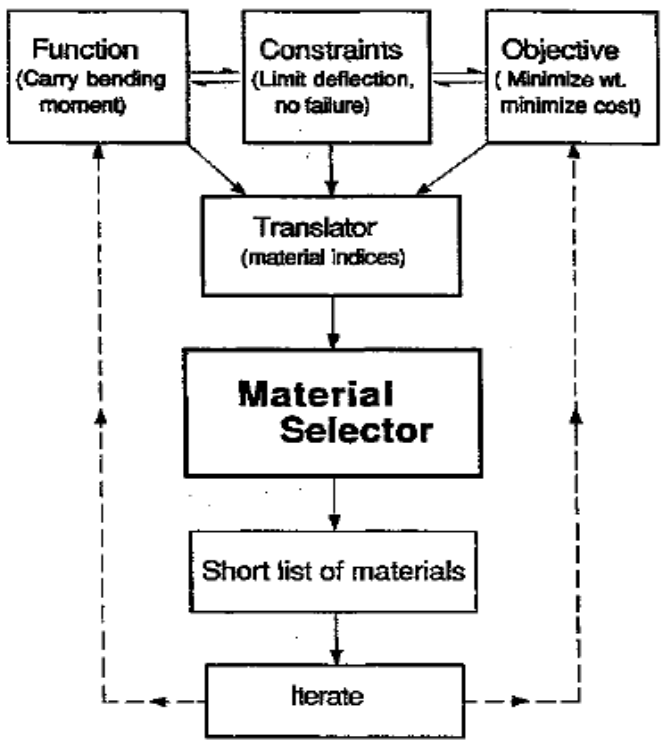

Fig 16. Design-led material selection

Based on the sequencial flow of activies [18] as show in fig.16 material selection of foldable bicycle frame has been done.

A. Translation: Foldable bicycle design requirement to the material selection.

Table 6: Translation: foldable bicycle

\begin{tabular}{|l|l|}
\hline Function & Light and strong \\
\hline Constraint & $\begin{array}{l}\text { No buckling or fatigue } \\
\text { caused by repeated cyclic } \\
\text { loads and length specified } \\
\text {. }\end{array}$ \\
\hline Objective & Minization of mass \\
\hline Free variable & $\begin{array}{l}\text { Material choice and cross } \\
\text { sectional area }\end{array}$ \\
\hline
\end{tabular}

Table 6. shows the translation of foldable bicycle .The material index was derived as mentioned in [18]. The lightest tube which performs the required function and meets the constraints is therefore that made from the material with the greatest value of the compound property or "index".

$$
M_{1}=\frac{\sigma}{\rho} \quad \longrightarrow \text { (1) }
$$

If the first constraint is that stiffness rather than strength, is that the index is below equation 2

$M_{2}=\frac{E}{\rho}$

B. Material selector.

The material index indicates the optimum solution in Asby chart-Density Vs young's modulus E (Gpa) and Density Vs Strength (Mpa).

C. Short listing of materials.

[18] The selected materials are Carbon-fiber composites. The CFRPs lie towards the upper right of Asby chart-Density Vs young's modulus E (Gpa) and Density Vs Strength (Mpa) chart. Metals steels, the alloys of aluminum, magnesium, and titanium lie almost on top each of each other in the chart; To separate them, the box in which they lie has been expanded horizontally to the right. It contains the alloys commonly used for bicycle frame: the low alloy steels 531 and 753; the aluminum alloy 7075, 2024, and 6061 in T4 or T6 condition; the relatively low-strength B265 titanium; and the magnesium alloy AZ61. All have almost identical values of (equation 1) M1 and (equation 2) M2

Based on the local feabilty Aluminum alloy 6061 T6 are selected.

\subsection{Material section - ASTM standards study

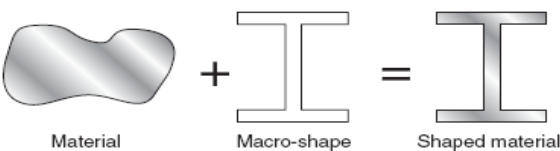

Fig 17. [19] Shaped material

Fig.17 Shows that the Mechanical efficiency is obtained by combining material with macroscopic shape. The shape of the Aluminum 6061 T6 has been studied in ASTM standards. The selected section overcomes the local product contraction constants. The selected sections are square and rectangular.

\subsection{FEA Analysis}

FEA is used to evaluate the fatigue failure of the proposed bicycle design. The failure locations and the cycles to failure is determined by FEA. The foldable bicycle frame is modeled and simulated in the CAD/CAE environment. The developed 3D cad model of foldable bicycle frame is show in fig.18.the tetrahedral element type has been used in this study for the FEA analysis. The number of elements are 150,000. The boundary conditions applied for the analysis is based on category 3 [17]. As a condition 3 bicycle, the frame is required to with stand $1200 \mathrm{~N}$ of tensile force and $6000 \mathrm{~N}$ of compression force. As the proposed design satisfies the criteria, the design is considered to be safe 


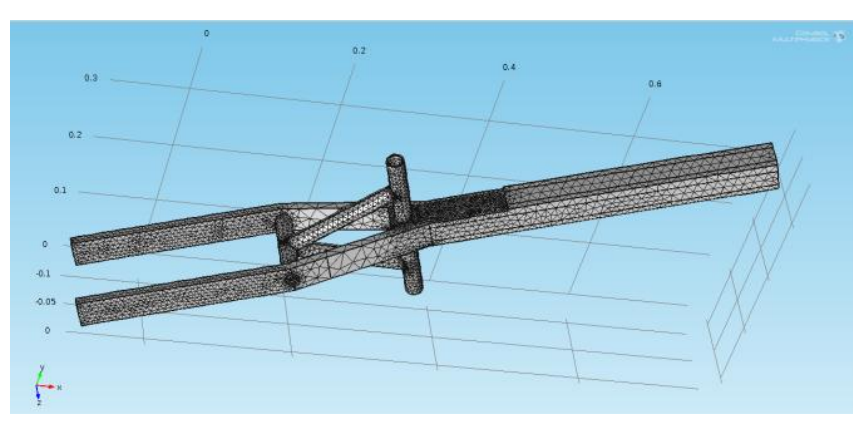

Fig 18. Cad model/meshed model

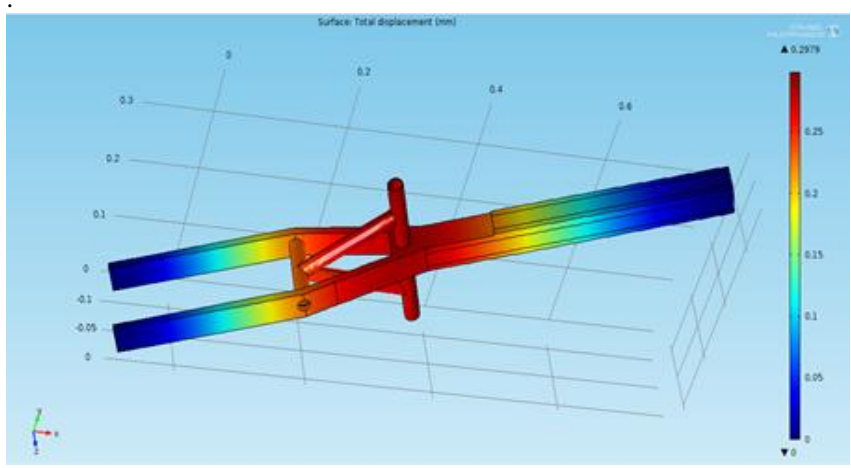

Fig 19. Static loading condition fea result

Fig. 19 show the FEA analysis result of foldable bicycle. The FEA result for the design is shown in table 4. The FEA result confirm that the proposed foldable bicycle frame design can withstand the static loading condition.

\subsubsection{Fatigue simulation}

The FEA analysis result in Fig.19 show that the propose bicycle design is safe under static loading conditions. The design has also been evaluated for the fatigue loading conditions in this study, by fatigue simulation. The Fatigue failure are generally classified into two categories such as high cycle fatigue failure and low cycle fatigue failure. [17] High cycle fatigue is defined as a failure that occurs from $10 \mathrm{e} 5$ to $10 \mathrm{e} 8$ cycles. High cycle fatigue tests are generally conducted at frequencies greater than $1,000 \mathrm{~Hz}$, making them unsuitable for bicycle testing. Low cycle fatigue failures on the other hand are failures that occur from 10 to $10 \mathrm{e} 5$ cycles. These cycles generally occur at a rate of $1 \mathrm{~Hz}$ or lower [21]. This test frequency is an accurate representation of the fatigue loading that a bicycle is seen in real world conditions.

The bicycle frame is required to withstand $1,200 \mathrm{~N}$ of tensile force and $600 \mathrm{~N}$ of compressive force for at least 50,000 cycles.

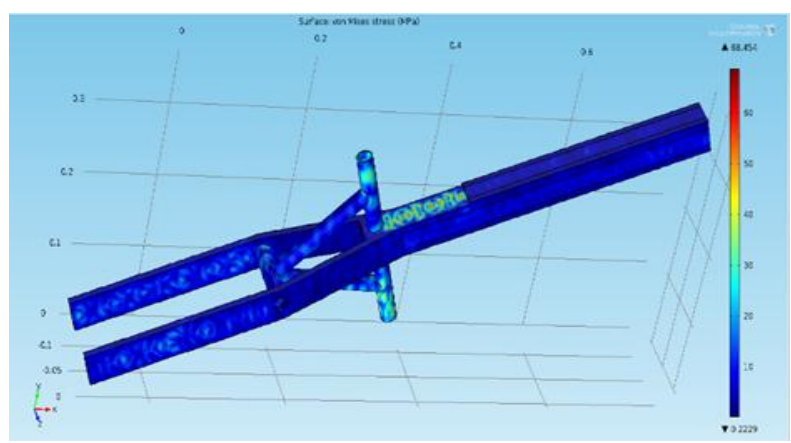

Fig 20. Fatigue simulation
Fig. 20 shows the fatigue simulation results. The values of the simulation results are show in table. 5. It assures that the frame can withstand the real world loading conditions.

\subsection{CAD model}

The CAD model is the input when the product evolves to the production stage of the product design and development process. The final 3D CAD model of the proposed design is show in fig. 23. It contains the various parts like saddle, chain drive, handle bar front/rear wheel etc. the joint and links have been incorporated in order to provide foldability as well as portability.

Fig. 21 -Shows the disassembled view of the foldable bicycle. This view shows the ease of disassembly of the proposed design, which aids in the ease for foldability.

Fig.22 - Shows the saddle and handle bar adjustability view, which aids in using the proposed concept by different age groups.

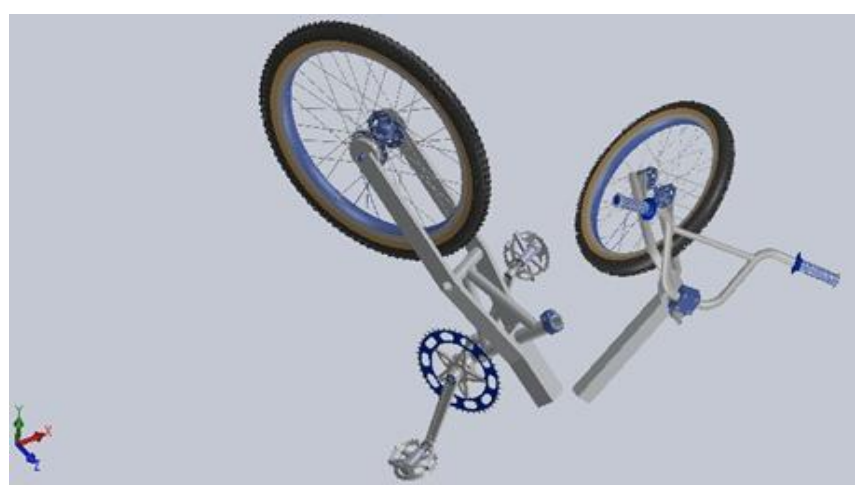

Fig 21. Disassembled View of foldable bicycle

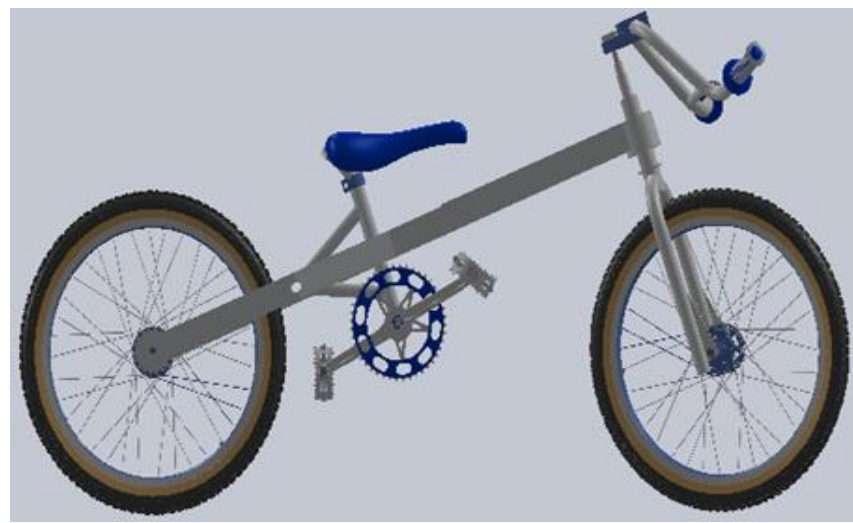

Fig 22. Saddle and Handle Bar Adjustability View

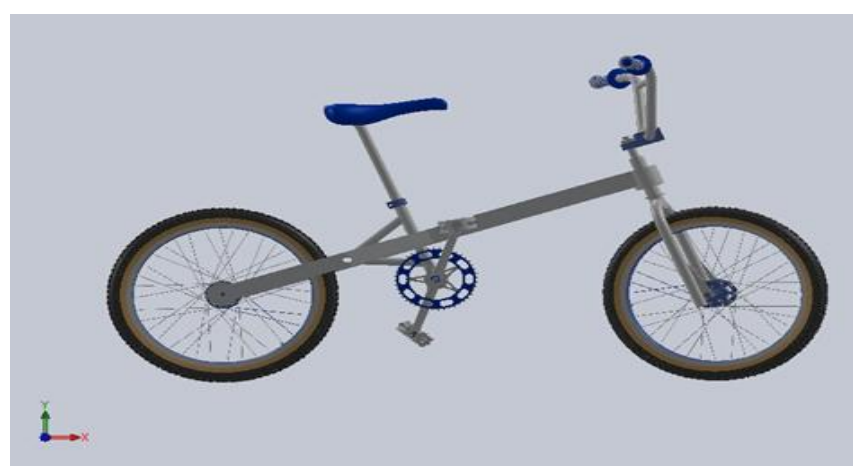

Fig 23. Final Assembly Foldable bicycle CAD Model 


\section{CONCLUSION}

In this study, a novel foldable bicycle design has been developed. The proposed design has good portability and foldability when it is compared with the existing bicycles. The design has been evaluated with existing designs using Pugh chart/numerical scoring methods The DHM technology has been used to check the human comfort like knee clearance, hand reach, foot reach, etc. The selected material during embodiment design stage have been validated by FEA analysis under static and dynamic loading conditions.

\section{FUTURE WORK}

The Current study, deals with a conceptual and embodiment design of a foldable bicycle of foldable bicycle design. The downstream activities in the product development process like bill of material product cost analysis, proof of concept have to be developed.

\section{REFERENCES}

[1] Nishimura et al, "Foldable bicycle frame", United States patent, Japan, 4/1986, 4579360.

[2] Beech, "Foldable exercise cycle", United States patent, United States, 11/1986, 4632386.

[3] Chiu, "Mini Foldable cycle", United States patent, New York, 4/1989, 4824130.

[4] Huppe, "Bicycle with universal adjustable frame", United States patent, Florida, USA, 7/1990, 5072961.

[5] Ching-Tsung yeh, "Foldable bicycle", United States patent, china, 3/1995, 5398955.

[6] Herder, "Foldable bicycle frame", United States patent, Australia, 3/2000, 6032971.

[7] Ibarra, "Skateboard-bicycle combination", United States patent, CA (US), 6/2001, US 6250656 B1.

[8] Sanders, "Foldable cycle", United States patent, Windsor, UK, 9/2007, US 7264257 B2
[9] Yi-Cheng Lin, "Structure for laterally moving a folded folding bicycle", United States patent application publication, Taichung, 8/2010, US 2010/0253040 A1.

[10] Zane et al, "Clamp for holding bicycle lock", United States patent, Boston, 4/1988, 4736921.

[11] Jeng, "Joint for a bicycle frame", United States patent, Taiwan, 2/1990, 4902160.

[12] Pan, "Foldable frame member for a foldable bicycle", United States patent, Taiwan, 2/1996, 5492350.

[13] Kevin Otto and Kristin wood, Product design-Techniques in reverse engineering and new product development, Pearson Education, India, 2006

[14] Yousef Haik, Engineering Design Process, Cengage Learning, India, 1997.

[15] Debkumar chakrabarti, Indian anthropometric dimensions for ergonomics design practice India, National Institute of design, India, 1999,ISBN 81-86199-15-0.

[16] Lambros laios and John giannatsis, "Ergonomic evaluation and redesign of children bicycle based on anthropometric data", Applied Ergonomics 41(2010) 428-435.

[17] Forrest dwyer, Adrian Shaw and Richard Tombarelli, "Material and design optimization for an aluminium bike frame", Worcester polytechnic institute, 4/2012.

[18] M.F Ashby, "Material, Bicycle and Design", Edward demile Campbell memorial lecture ASM international, USA, 1994.

[19] Michael F.Ashby, Material selection in mechanical design- $4^{\text {th }}$ edition, Elsevier publication, India, 2011.

[20] J.Sanjog, S. Karmakar, H.Agarwal, and C.D patail, "Deigning and Ergonomic evaluation of a shoe-rack in CAD environment", International journal of computer applications (0975-8887), Vol.49, no.20, pp. 38-41, 2012.

[21] Kuhn, Howard, and Dana Medlin. "Mechanical Testing and Evaluation". Materials Park, OH: ASM International, 2000. Print. 